\title{
Hematopoietic stem cell transplantation for Hodgkin's disease
}

\author{
Poliana Patah ${ }^{1}$ \\ Luis Fayad ${ }^{2}$ \\ Marcos de Lima $^{3}$
}

${ }^{1}$ Cancer Center, Hospital Sírio Libanês, São Paulo (SP), Brazil 2Department of Lymphoma and Myeloma, The University of Texas M.D. Anderson Cancer Center, USA

${ }^{3}$ Department of Stem Cell Transplantation and Cell Therapy, The University of Texas M.D. Anderson Cancer Center, USA

Submitted: $1 / 25 / 2011$

Accepted: 1/25/2011

Correspondence: Poliana Patah Hospital Sírio Libanês, Centro de Oncologia Rua Dona Adma Jafet, 91 - Bela Vista 01308-050 - São Paulo ( SP), Brazil Phone: $55113155-0200$

polipatah@gmail.com

www.rbhh.org or www.scielo.br/rbhh

DOI: $110.5581 / 1516-8484.20110004$
Autologous stem cell transplantation (aHSCT) has been considered the "gold standard" treatment following salvage chemotherapy for relapsed or refractory Hodgkin's lymphoma. The first randomized trial comparing conventional chemotherapy and aHSCT was published in 1993. ${ }^{(1)}$ Forty patients received BCNU, etoposide, cytarabine, and melphalan (BEAM) as conditioning regimen followed by aHSCT or "mini-BEAM" in the chemotherapy arm. The results indicated the superiority of transplantation. The European Group for Blood and Marrow Transplantation published a confirmatory randomized study ( $\mathrm{n}=161$ patients), in which dexa-BEAM was chosen for the chemotherapy control arm. ${ }^{(2)}$ With a median follow-up of 3 years, event-free survival (EFS) was $55 \%$ versus $34 \%$ for the transplant and chemotherapy arms, respectively, reinforcing the recommendation that high-dose chemotherapy with aHSCT rescue should be the treatment of choice for relapsed or refractory disease.

Several models have been employed to predict outcomes in patients with relapsed/ refractory Hodgkin's lymphoma who undergo high-dose chemotherapy followed by aHSCT. Moskowitz et al. proposed the use of three factors: complete remission $<1$ year, presence of B-symptoms and extranodal disease at the time of relapse. Patients with 0-1 risk factors had an EFS of $83 \%$, while patients with 2 and 3 factors had EFS of $27 \%$ and $10 \%$, respectively. ${ }^{(3)}$ More recently, functional studies to assess chemosensitivity (FI; PET scan, Ga67 scan) performed before transplant have become excellent prognostic tools. ${ }^{(4,5)}$ Persistence of positive FI before aHSCT identifies a group of patients who will have a worse outcome than those with negative FI after finishing salvage chemotherapy.

Chemosensitive disease has better outcomes with autologous transplants, given the higher relapse and toxicity rates among chemorefractory patients. Several approaches have been proposed to overcome this barrier, including tandem transplants. In this approach, patients are submitted to two sequential autologous transplants, usually within one to three months. An investigation by the German Hodgkin Lymphoma Study Group enrolled 43 primary refractory or very unfavorable relapse patients. Patients received salvage chemotherapy with ifosfamide, etoposide and woxorubicin (IVA), underwent stem cell collection and two tandem transplants. ${ }^{(6)}$ Conditioning regimen for the first aHSCT consisted of CBV plus mitoxantrone, while the second transplant was with cytarabine $6 \mathrm{~g} / \mathrm{m}^{2}$, melphalan $140 \mathrm{mg} / \mathrm{m}^{2}$ and total body irradiation of $12 \mathrm{~Gy}$, or busulfan $12 \mathrm{mg} / \mathrm{kg}$. Four patients had no response to salvage therapy, seven patients received only one transplant and 32 patients completed the initially planned treatment. Among the 24 patients with unfavorable relapses, 20 achieved complete remission and among the 19 patients with induction failure, ten were in remission. The 2-year survival from the date of progression was $65 \%$ for the whole study population, while it was $74 \%$ for the 32 patients who completed the treatment.

The Groupe d'Etude des Lymphomes de l'Adulte (GELA) treated 245 patients with relapsed disease -150 of which had primary refractory or very high-risk disease - with a protocol including IVA or MINE for salvage, and single or tandem autologous transplants. ${ }^{(7)}$ Patients with standard risk received the first transplant only, while primary refractory or very high-risk patients proceeded to tandem transplants. The first conditioning regimen included cyclophosphamide, carmustine, etoposide and mitoxantrone, while the second transplant, performed 45 to 90 days after the first, used total body irradiation at $12 \mathrm{~Gy}$, cytarabine and melphalan, or busulfan-based preparative regimen, similar to the German study. With a median follow-up of 51 months, in an intention to treat analysis, 5-year progression-free and overall survival were $46 \%$ and $57 \%$ for high-risk patients, and $73 \%$ and $85 \%$ for the standard risk group, respectively. In addition, the 5 -year overall survival for patients with chemotherapy-resistant disease was $46 \%$ (as opposed to an expected rate of $30 \%$ observed in previous studies). These results would 
suggest that patients who do not respond well to salvage chemotherapy or for early (occurring less than 1 year after achievement of remission), unfavorable relapses, tandem transplants may be superior to standard single aHSCT. There are several unresolved controversies surrounding this issue, however, and this recommendation is not universally accepted.

Allogeneic transplants have been explored in younger patients who relapse following aHSCT, but are still considered experimental and should be performed within a clinical trial. There is still controversy as to whether a graftversus Hodgkin's disease effect exists. However, long-term survival rates of $10-40 \%$ have been reported for selected patients. For those without matched related or unrelated donors, several centers are investigating haploidentical (mismatched related) or unrelated cord blood transplantation. Outcomes are better for chemosensitive patients, especially for those that achieve complete remission prior to transplant. ${ }^{(8-10)}$ Non-transplant options include everolimus, and the immunotoxin, brentuximab vedotin drugs that have recently been shown to have activity in relapsing/refractory Hodgkin's lymphoma.

In summary, patients with relapsed disease should be referred for transplantation. Hodgkin's lymphoma, however, remains a challenging disease for the minority of patients that are not cured after initial chemotherapy.

\section{References}

1. Linch DC, Winfield D, Goldstone AH, Moir D, Hancock B, McMillan A, et al. Dose intensification with autologous bonemarrow transplantation in relapsed and resistant Hodgkin's disease: Results of a BNLI randomised trial. Lancet. 1993;341 (8852):1051-4.

2. Schmitz N, Pfistner B, Sextro M, Sieber M, Carella AM, Haenel M, Boissevain F, Zschaber R, Müller P, Kirchner H, Lohri A, Decker S, Koch B, Hasenclever D, Goldstone AH, Diehl V; German Hodgkin's Lymphoma Study Group; Lymphoma Working Party of the European Group for Blood and Marrow Transplantation. Aggressive conventional chemotherapy compared with high-dose chemotherapy with autologous haemopoietic stem-cell transplantation for relapsed chemosensitive Hodgkin's disease: a randomised trial. Lancet. 2002;359(9323):2065-71.
3. Moskowitz CH, Nimer SD, Zelenetz AD, Trippett T, Hedrick EE, et al. A 2-step comprehensive high-dose chemoradiotherapy second-line program for relapsed and refractory Hodgkin disease: analysis by intent to treat and development of a prognostic model. Blood. 2001;97(3):616-23.

4. Jabbour E, Hosing C, Ayers G, Nunez R, Anderlini P, Pro B, et al. Pretransplant positive positron emission tomography/gallium scans predict poor outcome in patients with recurrent/refractory Hodgkin lymphoma. Cancer. 2007;109(12):2481-9.

5. Moskowitz AJ, Yahalom J, Kewalramani T, Maragulia JC, Vanak JM, Zelenetz AD, et al. Pretransplantation functional imaging predicts outcome following autologous stem cell transplantation for relapsed and refractory Hodgkin lymphoma. Blood. 2010; 116(23):4934-7.

6. Josting A, Rudolph C, Mapara M, Glossmann JP, Sieniawski M, Sieber M, et al. Cologne high-dose sequential chemotherapy in relapsed and refractory Hodgkin lymphoma: results of a large multicenter study of the German Hodgkin Lymphoma Study Group (GHSG). Ann Oncol. 2005;16(1):116-23. Erratum in: Ann Oncol. 2008;19(8):1515. Sieniawski, M [corrected to Sieniawski, M].

7. Morschhauser F, Brice P, Fermé C, Diviné M, Salles G, Bouabdallah R, Sebban C, Voillat L, Casasnovas O, Stamatoullas A, Bouabdallah K, André M, Jais JP, Cazals-Hatem D, Gisselbrecht C; GELA/ SFGM Study Group. Risk-adapted salvage treatment with single or tandem autologous stem-cell transplantation for first relapse/ refractory Hodgkin's lymphoma: results of the prospective multicenter H96 trial by the GELA/SFGM study group. J Clin Oncol. 2008;26(36):5980-7.

8. Thomson KJ, Peggs KS, Smith P, Cavet J, Hunter A, Parker A, et al. Superiority of reduced-intensity allogeneic transplantation over conventional treatment for relapse of Hodgkin's lymphoma following autologous stem cell transplantation. Bone Marrow Transplant. 2008;41(9):765-70.

9. Sureda A, Robinson S, Canals C, Carella AM, Boogaerts MA, Caballero D, et al. Reduced-intensity conditioning compared with conventional allogeneic stem-cell transplantation in relapsed or refractory Hodgkin's lymphoma: an analysis from the Lymphoma Working Party of the European Group for Blood and Marrow Transplantation. J Clin Oncol. 2008;26(3):455-62. Comment in: J Clin Oncol. 2008;26(24):4045-6; author reply 4046-7.

10. Anderlini P, Saliba R, Acholonu S, Giralt SA, Andersson B, Ueno NT, et al. Fludarabine-melphalan as a preparative regimen for reduced-intensity conditioning allogeneic stem cell transplantation in relapsed and refractory Hodgkin's lymphoma: the updated M.D. Anderson Cancer Center experience. Haematologica. 2008;93 (2):257-64. 